\title{
Study of sand fly fauna in an endemic area of American cutaneous leishmaniasis and canine visceral leishmaniasis in the municipality of Espírito Santo do Pinhal, São Paulo, Brazil
}

\author{
Fernanda Elisa Colla-Jacques ${ }^{1 /+}$, Cláudio Casanova ${ }^{2}$, Ângelo Pires do Prado ${ }^{1}$ \\ 'Departamento de Biologia Animal, Universidade Estadual de Campinas, Campinas, SP, Brasil ${ }^{2}$ Superintendência de Controle \\ de Endemias, Secretaria de Estado da Saúde, São Paulo, SP, Brasil
}

\begin{abstract}
Canine American visceral leishmaniasis and American cutaneous leishmaniasis (ACL) cases have been recorded in Espirito Santo do Pinhal. The aim of this study was to gather knowledge of the sand fly community and its population ecology within the municipality. Captures were made weekly over a period of 15 months in the urban, periurban and rural areas of the municipality, using automatic light traps. A total of 5,562 sand flies were collected, comprising 17 species. The most abundant species were Nyssomyia whitmani and Pintomyia pessoai in the rural area, Lutzomyia longipalpis and $\mathrm{Ny}$. whitmani in the periurban area and Lu. longipalpis in the urban area. The highest species richness and greatest index species diversity were found in the rural area. The similarity index showed that urban and periurban areas were most alike. Lu. longipalpis was found in great numbers during both dry and humid periods. The presence of dogs infected with Leishmania infantum chagasi in the urban area indicates a high risk for the establishment of the disease in the region. A high abundance of $\mathrm{Ny}$. whitmani and $\mathrm{Pi}$. pessoai in the rural and periurban areas indicates the possibility of new cases of ACL occurring in and spreading to the periurban area of Espírito Santo do Pinhal.
\end{abstract}

Key words: leishmaniasis - sand fly - ecology - Lutzomyia

Although leishmaniasis cycles involve several species of Leishmania, mammalian hosts and sand fly vectors, their peculiar epidemiology in the New World seems to follow a basic pattern, in which the size of the area occupied by the vector, its abundance, dispersion pattern and feeding behaviour are considered determinants in the link between human and enzootic cycles (Shaw \& Lainson 1987, Lainson 1989). Knowledge of the sand fly community, its population dynamics and its environmental distribution is essential in understanding the role of different species in the transmission cycles of Leishmania and in developing more efficient control strategies.

In Brazil, over 229 species of sand flies have been documented, with 19 considered to be either possible or proven vectors of human-infecting Leishmania (Rangel \& Lainson 2003, Shimabukuro 2007). In state of São Paulo (SP), 66 species are present (Galati 2003, Shimabukuro 2007), of which seven are considered to be epidemiologically important. Nyssomyia intermedia (Lutz \& Neiva 1912), Nyssomyia neivai (Pinto 1926), Nyssomyia whitmani (Antunes \& Coutinho 1939), Migonemyia migonei (França 1920), Pintomyia pessoai (Coutinho \& Barreto 1940) and Pintomyia fischeri (Pinto 1926) have been indicated as probable vectors of Leishmania (Viannia) braziliensis, the main causative agent of American cutaneous leishmaniasis (ACL) in the state, due to their

Financial support: SUCEN, CNPq (based on MSc dissertation)

+ Corresponding author: fernandacolla@gmail.com

Received 3 November 2009

Accepted 5 February 2010 anthropophilic behaviour and high abundance in localities with human cases of disease, among other ecological aspects (Gomes et al. 1989, Gomes 1994, Tolezano 1994, Casanova et al. 1995, 2009, Galati et al. 1996, Katz 1997, Mayo et al. 1998, Andrade Filho et al. 2007). In the Campinas region, 618 cases of ACL have been reported since 1998 and 16 of those were in Espírito Santo do Pinhal. Preliminary studies showed that the six species mentioned above, except $N y$. intermedia, have been identified in the rural area of Espírito Santo do Pinhal and that some of these species have also been found in the urban and periurban areas (unpublished observations). Understanding the environmental distribution of these populations may help to identify and monitor the areas most at risk from ACL.

Lutzomyia longipalpis (Lutz \& Neiva 1912) is the main vector of Leishmania infantum chagasi (Cunha \& Chagas 1937), the American visceral leishmaniasis (AVL) causative agent and is now present in all Brazilian Regions (Souza et al. 2009). Its first occurrence within an urban area of SP was in Araçatuba in 1997 (Costa et al. 1997) and, since then, a clear expansion of its distribution area has been recorded. At present, this species has been registered in the urban area of 107 municipalities, with Espírito Santo do Pinhal being the only one in the northeast area of SP. The high abundance of the vector, coupled with canine transmission, has been indicated as a precursor to the occurrence of autochthonous human cases in the urban area of SP. From 1999-2009, 1,539 human cases, with 134 resulting in death, were reported within the state. Lu. longipalpis was first collected in the rural area of Espírito Santo do Pinhal in 1994 and in the urban area in 2000 (Casanova et al. 2006). So far, only 
canine cases of AVL have been recorded in the urban regions (SES/SUCEN/CCD 2008). The Lu. longipalpis population of Espírito Santo do Pinhal is characterised by a sex pheromone that differs from that found in populations from the western region of SP (Casanova et al. 2006). Identifying population parameters that indicate vector capacity is essential to understanding the different epidemiological patterns of AVL within the state.

This study aimed to characterise the sand fly communities from different areas (rural, periurban and urban) of Espírito Santo do Pinhal and record the monthly population variations of the most frequent species.

\section{MATERIALS AND METHODS}

Study area - The municipality of Espírito Santo do Pinhal $\left(22^{\circ} 06^{\prime} \mathrm{S} 46^{\circ} 26^{\prime} \mathrm{W}\right)$ is located in the northeast area of SP, $200 \mathrm{~km}$ from the capital (Fig. 1). It has an area of $391.4 \mathrm{~km}^{2}$ and approximately 45,000 inhabitants. According to Köeppen's climate classification, the region is identified as Cwa (humid subtropical climate with dry winter) (CEPAGRI 2009). The rural area is characteristically mountainous with rocky outcrops, comprising large areas used for growing coffee and smaller areas used for subsistence farming.

The municipality elevation varies from $800-1.200 \mathrm{~m}$ above sea level. As a result, the region can be divided into two distinct climate types: altitude subtropical climate, found in mountainous areas near the state of Minas Gerais boundary (900-1.200 m high), and where the average temperature varies from $16-18^{\circ} \mathrm{C}$, and tropical climate, located near the Mogi Guaçu River depression, which is the lowest area of the district (800-900 $\mathrm{m}$ high) and where the summers are hot and the average temperature is around $23^{\circ} \mathrm{C}$.

Sand fly collection - Over the course of 15 months, from November 2006-January 2008, weekly collections using CDC traps were carried out from $6 \mathrm{pm}-7$ am in properties located in the urban, periurban and rural areas of the municipality. A total of 17 properties were studied: four rural, five periurban and eight urban. Although the collection was performed weekly, the data is presented in $15 \mathrm{~d}$ increments, with six samples from each area considered for each period.

The flies were taken to the Superintendência de Controle de Endemias laboratory, in Mogi Guaçu-SP, where they were processed according to Forattini (1973) and identified using Galati's (2003) classifications. Some of these specimens were added to the entomological collection of the Departamento de Epidemiologia of the Faculdade de Saude Pública, Universidade de São Paulo.

Analysis - The frequency of each species among the collected sand flies was calculated for each of the three studied areas. The male-to-female ratio was determined for the total number of sand flies captured and for each species individually. The diversity was obtained using species richness and Margalef's Index $\left(D_{M}\right)$ and the similarity between the different areas was calculated by Morisita's Index $\left(\mathrm{S}_{\mathrm{M}}\right)$ (Brower \& Zar 1984, Magurran 1988, Service 1993).
The estimates of evenness were obtained using Pielou's index (Magurran 1988). The standardised index of species abundance (SISA) was calculated according to Roberts and Hsi (1979) and the species constancy was calculated by the constancy coefficient (Dajoz 1973). For the most abundant species, the monthly distribution was analysed relative to the $10 \mathrm{~d}$ soil water balance (Thornthwaite \& Mather 1955). Climate related data was provided by CIIAGRO (2009).

\section{RESULTS}

At the end of the 15 month study period, 5,562 sand flies were collected, comprising of four subtribes (Brumptomyiina, Sergentomyiina, Lutzomyiina and Psychodopygina), 10 genus and 17 species: Lu. longipalpis, $N y$. whitmani, Ny. neivai, Evandromyia lenti (Mangabeira 1938), Evandromyia cortelezzii (Brethes 1923), Evandromyia termitophila (Martins, Falcão \& Silva 1964), Evandromyia edwardsi (Mangabeira 1941), Mg. migonei, Pi. fischeri, Pi. pessoai, Pintomyia monticola
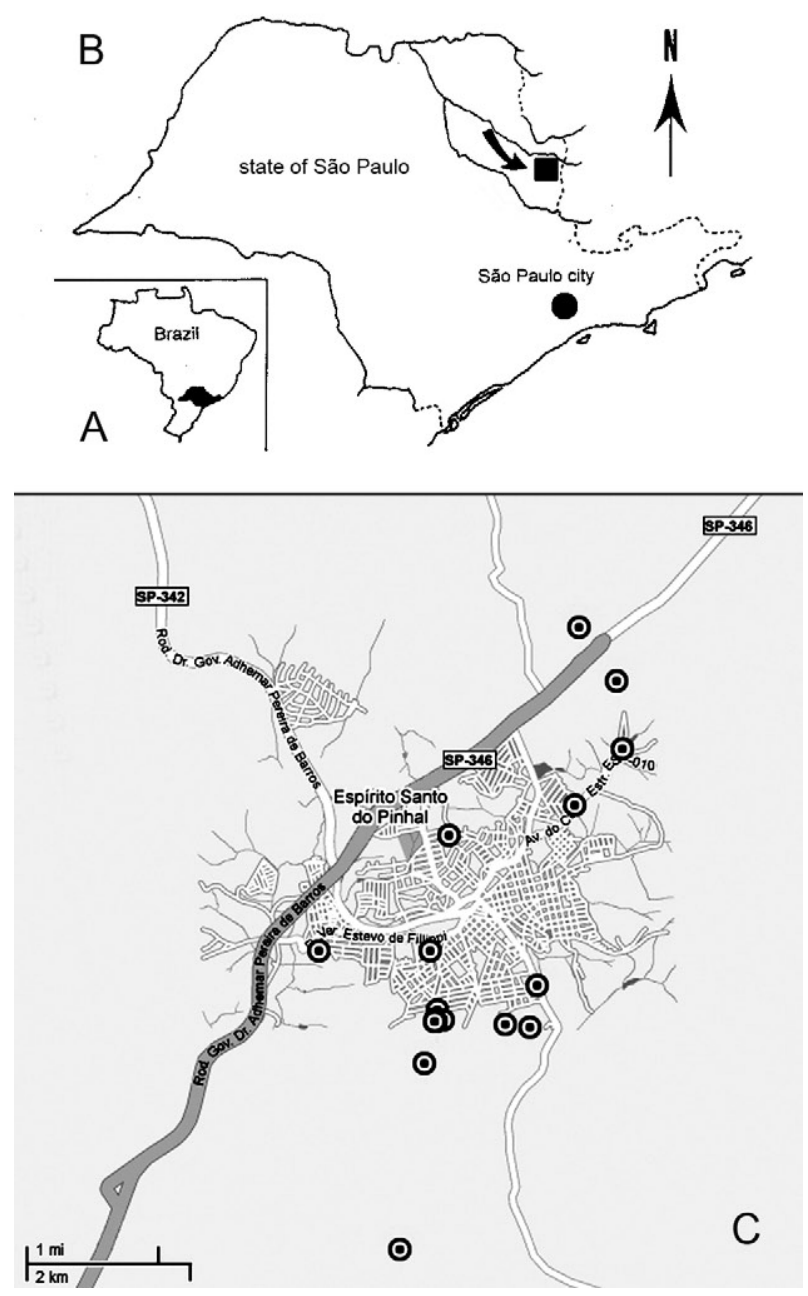

Fig. 1: study area: A: Brazil; B: state of São Paulo; C: municipality of Espírito Santo do Pinhal. 
(Costa Lima 1932), Sciopemyia sordellii (Shannon \& Del Ponte 1927), Micropygomyia quinquefer (Dyar 1929), Psathyromyia aragaoi (Costa Lima 1932), Expapillata firmatoi (Barretto, Martins \& Pellegrino 1956), Brumptomyia cunhai (Mangabeira 1942) and Brumptomyia avellari (Costa Lima 1932) (Table I).

Of the four subtribes found in the study area, Lutzomyiina was both the most frequent, accounting for $62.8 \%$ of all sand flies and the most diverse, represented by six genera. The male-to-female ratio was 2.14 , varying from 5.75 for Lu. longipalpis to 0.13 for Mi. quinquefer. In the case of five species, sand flies of both sexes were not captured: no males for Ev. termitophila, $E v$. edwardsi and Pi. monticola, and no females for $B r$. cunhai and Br. avellari.

Seventeen species were found in Espírito Santo do Pinhal, with representatives from each species collected within the first two months of the study. The rural area showed the highest richness, with all 17 species found there. The richness encompassed 13 species in the periurban area and in the urban area, eight (Fig. 2).

The greatest number of sand flies was captured in rural area. A total of 2,594 individuals $(46.6 \%)$ were present in the rural area, followed by $2,316(41.6 \%)$ in the periurban area and $652(11.7 \%)$ in the urban area. $N y$. whitmani and Lu. longipalpis were the species with the highest number of collected sand flies, with 1,999 $(35.9 \%)$ and $1,828(32.9 \%)$ individuals, respectively. Other species, such as Pi. pessoai (14.9\%), Mg. migonei (7.4\%) and Ev. lenti (5.1\%) were also collected in high numbers in the three areas (Table I).

When applied to the municipality as a whole, the SISA showed that $N y$. whitmani and Lu. longipalpis were the most abundant species with values of 0.86 and 0.84 , respectively (Table II). In the rural area, $N y$. whitmani was the predominant species, with 1,127 flies (43.5\%), followed by Pi. pessoai, with 744 (28.7\%), and Mg. migonei, with 347 (13.4\%) (Table I). Their SISA values were $0.98,0.88$ and 0.74 , respectively. In the periurban area, $\mathrm{Lu}$. longipalpis was the predominant species, with 1,209 flies (52.2\%), followed by $N y$. whitmani (838 flies, 36.2\%), Pi. pessoai (79, 3.41\%) and $M g$. migonei $(60,2.59 \%)$. Their SISA values were 0.77, 0.73,

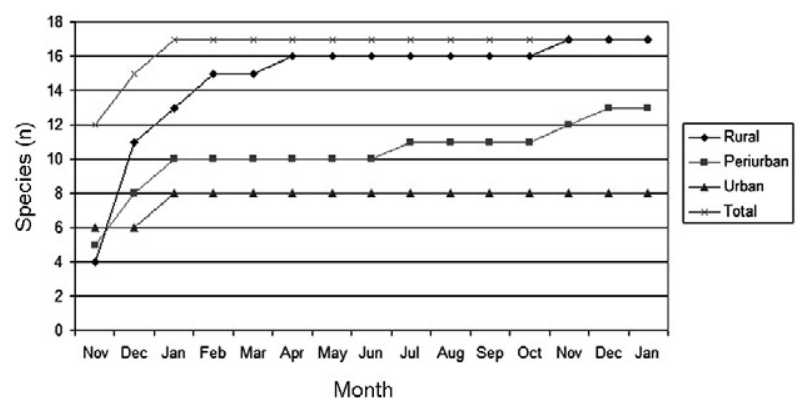

Fig. 2: number of species collected in Espírito Santo do Pinhal from November 2006-January 2008.
0.46 and 0.41 , respectively. As in the periurban area, $\mathrm{Lu}$. longipalpis was the predominant species in the urban area, with 476 individuals (73\%) and a SISA value of 0.98 . The next-most frequently found species in the urban area were $E v$. lenti, with 114 sand flies (17.5\%), $N y$. whitmani, with 34 (5.21\%) and Ev. cortelezzii, with $16(2.45 \%)$. Their SISA values were $0.58,0.50$ and 0.29 , respectively (Table II).

The greatest numbers of $N y$. whitmani flies were collected in February 2007, and the smallest in June and July of the same year (Fig. 3A). These months corresponded to the period after the water balance surplus and to the period before the long water deficit, respectively (Fig. 4). Both Pi. pessoai and Mg. migonei showed the same fluctuation pattern (Fig. 3B, C). $L u$. longipalpis had an unusual pattern compared to those of the other species, having large population fluctuations throughout the study that alternated between high and low abundances; however, peaks in its population were still observed, occurring in April and November of 2007 (Fig. 3D).

The seasonal distribution of the species found in Espírito Santo do Pinhal can also be assessed using the constancy coefficient, which classifies each species according to the number of collections in which it is present. Ny. whitmani, Mg. migonei and Pi. pessoai were constant species in the rural areas. Only Lu. Longipalpis, however, could be considered a constant species in both the urban and periurban areas (Table III).

The number of species and the number of sand flies collected in each area were used to calculate the $\mathrm{D}_{\mathrm{M}}$ diversity index. Consistent with species richness, the $D_{M}$ diversity index indicated that the rural area was the most diverse $\left(D_{M}=2.04\right)$ and the urban was the least diverse $\left(D_{M}=1.08\right)$, with the diversity of the periurban area in the middle $\left(\mathrm{D}_{\mathrm{M}}=1.55\right)$. The evenness indices were 0.53 for the rural area, 0.45 for the periurban area and 0.42 for the urban area.

When compared to each other using $\mathrm{S}_{\mathrm{M}}$ similarity coefficient, the urban and periurban areas were found to be more similar to each other $\left(\mathrm{S}_{\mathrm{M}}=0.83\right)$ than either was to the rural area. The similarity between the periurban and the rural areas was 0.57 and 0.17 between the urban and rural areas.

\section{DISCUSSION}

Each of the 17 species collected in Espírito Santo do Pinhal had previously been recorded in SP (Galati 2003, Shimabukuro 2007); however, the species richness in this study represents a much more diverse fauna when compared to previous works carried out in the study area (Gomes et al. 1989, Rangel \& Vido 1997, Casanova et al. 2009). In addition, these findings, in which $N y$. whitmani and Lu. longipalpis were the most abundant species, contrast with those of previous studies, which identified $N y$. neivai as the predominant species in the Mogi Guaçu River drainage basin (Gomes et al. 1989, Casanova et al. 2005, 2009).

Lutzomyiina was the most abundant subtribe identified in this study, whereas Psychodopygina was the most abundant subtribe found in previous records (Silva et al. 
TABLE I

Male and female sand flies captured in municipality of Espírito Santo do Pinhal, state of São Paulo and their frequencies per area from November 2006-January 2008

\begin{tabular}{|c|c|c|c|c|c|c|c|c|c|c|c|c|}
\hline \multirow[b]{2}{*}{ Subtribe/species } & \multicolumn{3}{|c|}{ Rural } & \multicolumn{3}{|c|}{ Periruban } & \multicolumn{3}{|c|}{ Urban } & \multicolumn{3}{|c|}{ Total } \\
\hline & M & $\mathrm{F}$ & $\%$ & M & $\mathrm{F}$ & $\%$ & M & $\mathrm{F}$ & $\%$ & M & $\mathrm{F}$ & $\%$ \\
\hline \multicolumn{13}{|l|}{ Lutzomyiina } \\
\hline Lutzomyia longipalpis & 126 & 17 & 5.51 & 1,035 & 174 & 52.20 & 396 & 80 & 73.01 & 1,557 & 271 & 32.87 \\
\hline Pintomyia fischeri & 28 & 25 & 2.04 & 7 & 3 & 0.43 & 0 & 0 & 0.00 & 35 & 28 & 1.13 \\
\hline Pintomyia pessoai & 526 & 218 & 28.68 & 47 & 32 & 3.41 & 3 & 0 & 0.46 & 576 & 250 & 14.85 \\
\hline Pintomyia monticola & 0 & 1 & 0.04 & 0 & 1 & 0.04 & 0 & 0 & 0.00 & 0 & 2 & 0.04 \\
\hline Evandromyia lenti & 55 & 59 & 4.39 & 29 & 25 & 2.33 & 44 & 70 & 17.48 & 128 & 154 & 5.07 \\
\hline Evandromyia cortelezzii & 14 & 11 & 0.96 & 4 & 12 & 0.69 & 7 & 9 & 2.45 & 25 & 32 & 1.02 \\
\hline Evandromyia termitophila & 0 & 5 & 0.19 & 0 & 0 & 0.00 & 0 & 0 & 0.00 & 0 & 5 & 0.09 \\
\hline Evandromyia edwardsi & 0 & 2 & 0.08 & 0 & 0 & 0.00 & 0 & 0 & 0.00 & 0 & 2 & 0.04 \\
\hline Migonemyia migonei & 203 & 144 & 13.38 & 33 & 27 & 2.59 & 2 & 2 & 0.61 & 238 & 173 & 7.39 \\
\hline Expapillata firmatoi & 5 & 6 & 0.42 & 0 & 1 & 0.04 & 0 & 0 & 0.00 & 5 & 7 & 0.22 \\
\hline Sciopemyia sordellii & 0 & 2 & 0.08 & 0 & 1 & 0.04 & 2 & 1 & 0.46 & 2 & 4 & 0.11 \\
\hline \multicolumn{13}{|l|}{ Psychodopygina } \\
\hline Nyssomyia whitmani & 641 & 486 & 43.45 & 546 & 292 & 36.18 & 18 & 16 & 5.21 & 1,205 & 794 & 35.94 \\
\hline Nyssomyia neivai & 2 & 0 & 0.08 & 0 & 5 & 0.22 & 0 & 0 & 0.00 & 2 & 5 & 0.13 \\
\hline Psathyromyia aragaoi & 4 & 5 & 0.35 & 0 & 0 & 0.00 & 0 & 0 & 0.00 & 4 & 5 & 0.16 \\
\hline \multicolumn{13}{|l|}{ Sergentomyiina } \\
\hline Micropygomyia quinquefer & 0 & 5 & 0.19 & 4 & 34 & 1.64 & 1 & 1 & 0.31 & 5 & 40 & 0.81 \\
\hline \multicolumn{13}{|l|}{ Brumptomyiina } \\
\hline Brumptomyia cunhai & 3 & 0 & 0.12 & 0 & 0 & 0.00 & 0 & 0 & 0.00 & 3 & 0 & 0.05 \\
\hline Brumptomyia avellari & 1 & 0 & 0.04 & 4 & 0 & 0.17 & 0 & 0 & 0.00 & 5 & 0 & 0.09 \\
\hline Total & 1,608 & 986 & & 1,709 & 607 & & 473 & 179 & & 3,790 & 1,772 & \\
\hline
\end{tabular}

F: female; M: male.
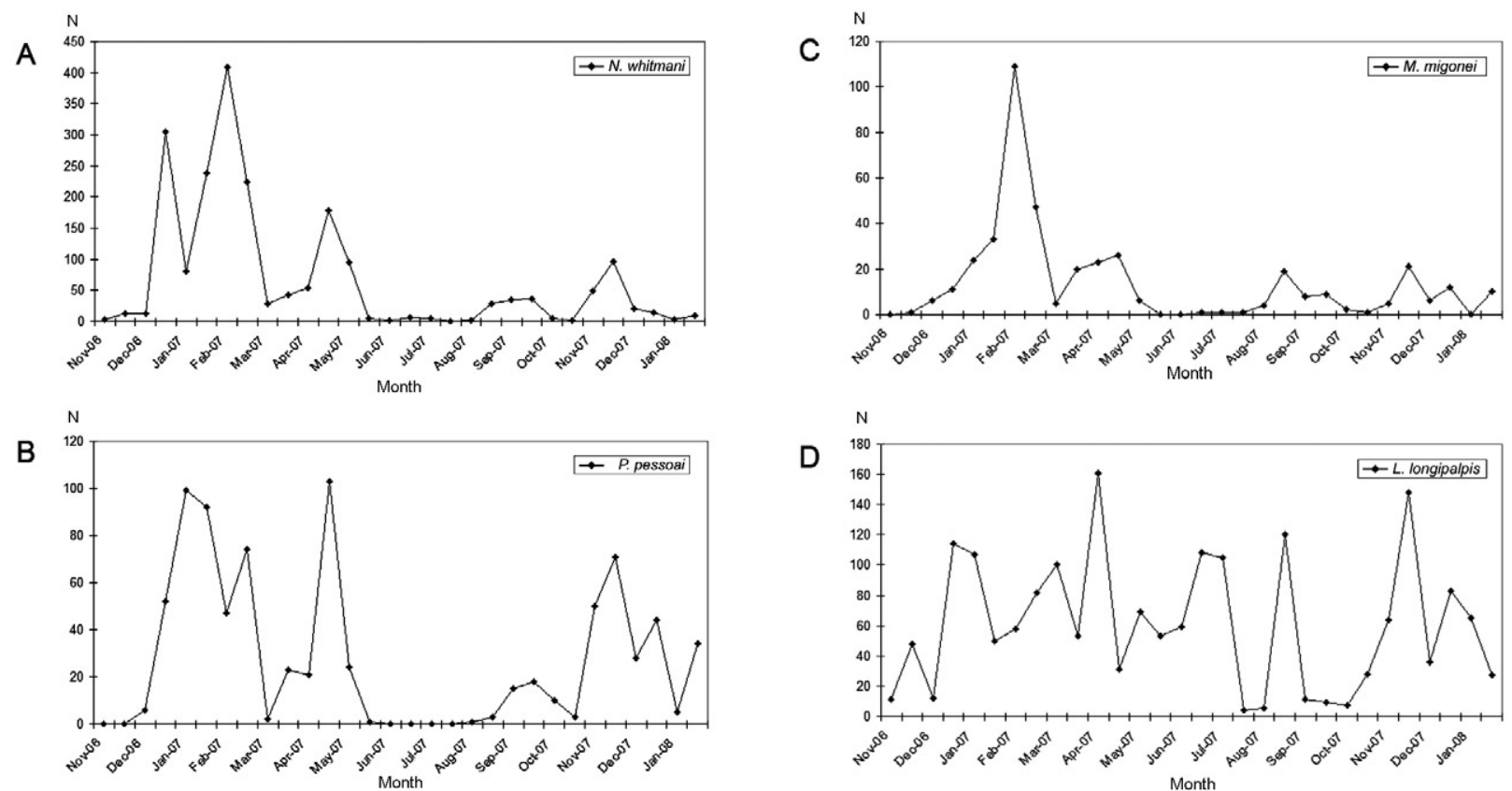

Fig. 3: fortnightly distribution of Nyssomyia whitmani (A), Pintomyia pessoai (B), Migonemyia migonei (C) and Lutzomyia longipalpis (D) in Espírito Santo do Pinhal from November 2006-January 2008. 
TABLE II

Standardized index of species abundance for sand flies collected in the rural, periurban and urban areas and the total, in Espírito Santo do Pinhal, from November 2006-January 2008

\begin{tabular}{|c|c|c|c|c|c|c|c|c|}
\hline \multirow[b]{2}{*}{ Species } & \multicolumn{2}{|c|}{ Rural } & \multicolumn{2}{|c|}{ Periurban } & \multicolumn{2}{|c|}{ Urban } & \multicolumn{2}{|c|}{ Total } \\
\hline & SISA & Position & SISA & Position & SISA & Position & SISA & Position \\
\hline Lutzomyia longipalpis & 0.44 & 7 th & 0.77 & $1 \mathrm{st}$ & 0.98 & $1 \mathrm{st}$ & 0.83 & 2nd \\
\hline Nyssomyia whitmani & 0.98 & $1 \mathrm{st}$ & 0.73 & $3 \mathrm{rd}$ & 0.50 & $3 \mathrm{rd}$ & 0.86 & $1 \mathrm{st}$ \\
\hline Evandromyia lenti & 0.52 & 6th & 0.68 & 4th & 0.58 & 2 nd & 0.71 & $3 \mathrm{rd}$ \\
\hline Evandromyia cortelezzii & 0.63 & 4th & 0.75 & 2nd & 0.29 & 4 th & 0.65 & 4th \\
\hline Migonemyia migonei & 0.74 & $3 \mathrm{rd}$ & 0.41 & 6 th & 0.19 & 5 th & 0.55 & 6th \\
\hline Pintomyia fischeri & 0.60 & 5 th & 0.10 & 9th & - & - & 0.33 & 7 th \\
\hline Pintomyia pessoai & 0.88 & 2nd & 0.46 & 5 th & 0.11 & 7 th & 0.57 & 5 th \\
\hline Sciopemyia sordellii & 0.13 & 11th & 0.02 & 11th & 0.15 & 6 th & 0.33 & 7 th \\
\hline Micropygomyia quinquefer & 0.22 & 9 th & 0.13 & 8 th & 0.09 & 8 th & 0.33 & 7 th \\
\hline Psathyromyia aragaoi & 0.16 & 10th & - & - & - & - & 0.22 & 10th \\
\hline Expapillata firmatoi & 0.37 & 8 th & 0.02 & 11 th & - & - & 0.26 & 8 th \\
\hline Brumptomyia cunhai & 0.12 & 12 th & - & - & - & - & 0.21 & 11 th \\
\hline Nyssomyia neivai & 0.04 & 14 th & 0.07 & 10 th & - & - & 0.21 & 11 th \\
\hline Evandromyia termitophila & 0.12 & 12 th & - & - & - & - & 0.21 & 11th \\
\hline Evandromyia edwardsi & 0.10 & 13 th & - & - & - & - & 0.21 & 11th \\
\hline Brumptomyia avellari & 0.02 & 15 th & 0.19 & 7 th & - & - & 0.24 & 9 th \\
\hline Pintomyia monticola & 0.02 & 15 th & 0.02 & 11 th & - & - & 0.20 & 12 th \\
\hline
\end{tabular}

SISA: standardised index of species abundance.

\section{TABLE III}

Species classification according to their constancy during the collections carried out in Espírito Santo do Pinhal, from November 2006-January 2008

\begin{tabular}{|c|c|c|c|c|}
\hline Species & Rural & Periurban & Urban & Total \\
\hline Lutzomyia longipalpis & $\mathrm{y}$ & $\mathrm{x}$ & $\mathrm{x}$ & $\mathrm{x}$ \\
\hline Nyssomyia whitmani & $\mathrm{x}$ & $\mathrm{y}$ & z & $\mathrm{x}$ \\
\hline Evandromyia lenti & $\mathrm{y}$ & $\mathrm{y}$ & $\mathrm{y}$ & $\mathrm{x}$ \\
\hline Evandromyia cortelezzii & z & $\mathrm{z}$ & z & $\mathrm{y}$ \\
\hline Migonemyia migonei & $\mathrm{x}$ & $\mathrm{y}$ & $\mathrm{z}$ & $\mathrm{x}$ \\
\hline Pintomyia fischeri & $\mathrm{y}$ & $\mathrm{z}$ & - & $\mathrm{y}$ \\
\hline Pintomyia pessoai & $\mathrm{x}$ & $\mathrm{y}$ & z & $\mathrm{x}$ \\
\hline Sciopemyia sordellii & $\mathrm{z}$ & $\mathrm{z}$ & $\mathrm{z}$ & $\mathrm{z}$ \\
\hline Micropygomyia quinquefer & $\mathrm{z}$ & z & z & $\mathrm{y}$ \\
\hline Psathyromyia aragaoi & $\mathrm{z}$ & - & - & $\mathrm{z}$ \\
\hline Expapillata firmatoi & z & $\mathrm{z}$ & - & $\mathrm{z}$ \\
\hline Brumptomyia cunhai & z & - & - & $\mathrm{z}$ \\
\hline Nyssomyia neivai & $\mathrm{z}$ & $\mathrm{z}$ & - & $\mathrm{z}$ \\
\hline Evandromyia termitophila & $\mathrm{z}$ & - & - & $\mathrm{z}$ \\
\hline Evandromyia edwardsi & $\mathrm{z}$ & - & - & $\mathrm{z}$ \\
\hline Brumptomyia avellari & $\mathrm{z}$ & z & - & $\mathrm{z}$ \\
\hline Pintomyia monticola & $\mathrm{z}$ & $\mathrm{z}$ & - & $\mathrm{z}$ \\
\hline
\end{tabular}

$\mathrm{x}$ : species present in more than $50 \%$ of the collections; $\mathrm{y}$ : species found in $25-50 \%$ of the collections; $\mathrm{z}$ : species found in less than $25 \%$ of the collections. 


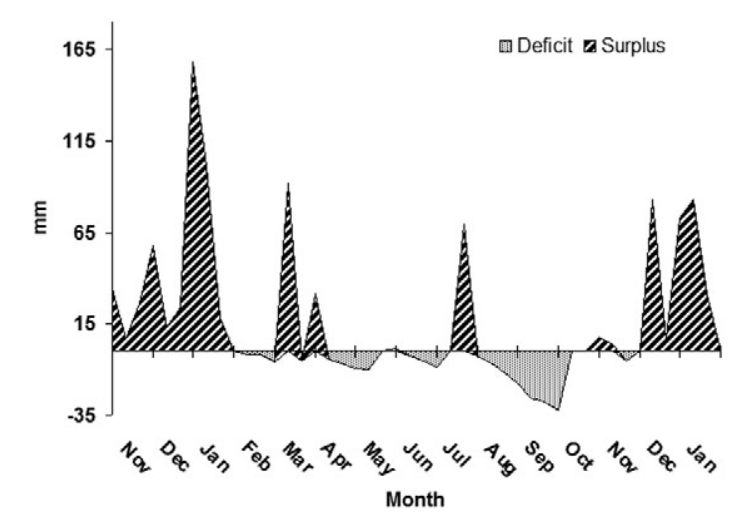

Fig. 4: $10 \mathrm{~d}$ soil water balance in Espírito Santo do Pinhal from November 2006-January 2008.

2008). The higher ratio of males to females has been observed before, mainly in areas where Lu. longipalpis is abundant (Oliveira et al. 2003, Galati et al. 2006, Resende et al. 2006). Gomes and Galati (1987) established a correlation between the number of male flies and a strategy to assure fecundation.

The rural area encompassed the greatest species richness and contained the largest number of sand flies in comparison to the other areas, which was expected given that there are more breeding sites and a greater ecotope diversity. Because it does not consider the number of sand flies collected, species richness does not provide an accurate description of the community in each area (Brower \& Zar 1984, Magurran 1988). The accumulated number of species shown relative to time, however, can be used as an indicator of the moment when the richness of an area was reached. This information can be useful in programming activities for the entomological control of a species that has epidemiological importance. In the urban area, the point of species richness was reached within the first two months of collections. In the rural and periurban areas, the curve took longer to stabilise, as new species were added during the last months of collection. Although usually underestimated, a one-year collection period represents a good sample for species richness in Espírito Santo do Pinhal.

The predominance of $N y$. whitmani and its abundance in the periurban area agree with other studies that indicated that this species is in the process of adapting to modified environments (Brazil et al. 1991, Azevedo et al. 1996). Of note, this species is considered the main vector of $L$. ( V.) braziliensis in several parts of Brazil (Mayrink et al. 1979, Carvalho et al. 2008). The high abundance of Ny. whitmani in February 2007 corresponded to the period immediately after a peak in the water supply and prior to the beginning of a long water deficit.

Vector population fluctuation is highly influenced by environmental conditions. Once adult population size reflects the outcome of birth rates and mortality in the immature stages, a correlation pattern between weatherrelated factors and adult monthly frequency is not always easily reached. Biotic and abiotic components of mortality that define the fluctuation or population regulation (Service 1993, Begon et al. 1996) must work differently for the early and adult sand fly stages, because they occupy different ecological niches. The combined effects of rainfall, air temperature, evapotranspiration and soil water balance likely influence the quality of the breeding habitats, consequently determining the fluctuations in the adult sand fly population (Rutledge \& Ellenwood 1975, Morrison et al. 1995, Ferro et al. 1997, Casanova et al. 2009).

Periods of moderate water surplus seem to be favourable for a population increase of the four most abundant species in Espírito Santo do Pinhal. In contrast, periods of high water surplus, even if short, seem to negatively affect those populations. The same effect occurs when there is a continuous water deficit, such as the one registered from the end of April 2007-October 2007. However, the short period of water surplus in July, during the dry season, seemed to create favourable conditions for a quick increase of the population. The fact that $L u$. longipalpis was found in great numbers during both dry and humid periods can be attributed to the more stable environmental conditions present in the urban area. Oliveira et al. (2003) also observed the presence of Lu. longipalpis during the entire year, higher population densities in those periods immediately following the rainy season. On the other hand, Resende et al. (2006) only registered high abundances immediately after periods with a high mean monthly rainfall.

One of the advantages of using $\mathrm{D}_{\mathrm{M}}$ diversity index is the simple calculation required; however, communities that show similar species and sand flies collected have the same $D_{M}$ without necessarily being identical (Brower \& Zar 1984, Magurran 1988, Service 1993). Consequently, evenness becomes an important population characteristic, as it measures how individuals are distributed amongst the species (Magurran 1988, Begon et al. 1996). The large species diversity in the rural area was expected due to the greater number of ecotopes found throughout more diverse environmental gradients and considering the availability of resources. The rural area includes residual forests, rocky outcrops and subsistence farms, as well as the animals that serve as blood sources for sand flies. On the other hand, the urban area contained the lowest diversity, due to the reduced availability of and homogeneity of resources. This type of environment favours specific populations that eventually become dominant, such as Lu. longipalpis. The higher evenness value for the rural area is probably related to the greater heterogeneity present in this environment, which allows for the adaptation of a greater number of species with a reduced abundance. The similarity between the periurban and urban areas may be related to the reduced diversity of breeding sites and ecotopes for immature forms that can result from a more homogeneous environment.

The data obtained by characterising communities from different areas, if applied more frequently, may provide a better understanding of the transmission dynamics of leishmaniasis and could be used to identify at-risk areas. The high abundance of species considered 
epidemiologically important, such as $N y$. whitmani, Pi. pessoai and Mg. migonei, in the rural area and their presence in the periurban area indicates a higher risk for the acquisition of ACL in these areas. Furthermore, the high abundance of $\mathrm{Lu}$. longipalpis in the urban area indicates that this species is well-adapted to an urbanised environment. Taken together with the identification of dogs infected with $L$. infantum chagasi in the municipality, these observations indicate that public health authorities should be concerned with the presence of Lu. longipalpis in the urban area, especially since these events usually precede human cases of AVL.

\section{REFERENCES}

Andrade Filho JD, Galati EAB, Falcão AL 2007. Nyssomyia intermedia (Lutz \& Neiva, 1912) and Nyssomyia neivai (Pinto, 1926) (Diptera: Psychodidae: Phlebotominae) geographical distribution and epidemiological importance. Mem Inst Oswaldo Cruz 102: 481-487.

Azevedo ACR, Vilela ML, Souza NA, Andrade-Coelho CA, Barbosa AF, Firmo ALS, Rangel EF 1996. The sand fly fauna (Diptera: Psychodidae: Phlebotominae) of a focus of cutaneous Leishmaniasis in Ilhéus, state of Bahia, Brazil. Mem Inst Oswaldo Cruz 91: 75-79.

Begon M, Harper JL, Townsend CR 1996. Ecology: individuals, populations and communities, 3rd ed., Blackwell Science, Oxford, 1068 pp.

Brazil RP, Morton IE, Ward RD 1991. Notes of the feeding habits of Lutzomyia (Nyssomyia) whitmani (Diptera: Psychodidade) in Ceará state, Northeast Brazil. Mem Inst Oswaldo Cruz 86: 497-498.

Brower JE, Zar JH 1984. Field \& laboratory methods for general ecology, 2nd ed., WCB, Dubuque, 226 pp.

Carvalho GML, Andrade Filho JD, Falcão AL, Rocha-Lima ACVM, Gontijo CMF 2008. Naturally infected Lutzomyia sand flies in a Leishmania-endemic area of Brazil. Vector Borne Zoonotic Dis 8: 407-414.

Casanova C, Hamilton JGC, Trigo JR, Costa AIP 2006. Identification of sex pheromones of Lutzomyia longipalpis (Lutz \& Neiva, 1912) populations from the state of São Paulo, Brazil. Mem Inst Oswaldo Cruz 101: 113-115.

Casanova C, Mayo RC, Rangel O, Mascarini LM, Pignatti MG, Galati EAB, Gomes AC 1995. Natural Lutzomyia intermedia (Lutz \& Neiva) infection in the valley of the Mogi Guaçu River, state of São Paulo, Brazil. Bol Dir Malariol San Amb 35 (Suppl.1): 77-84.

Casanova C, Natal D, Santos FAM 2009. Survival, population size and gonotrophic cycle duration of Nyssomyia neivai (Diptera: Psychodidae) at an endemic area of American cutaneous leishmaniasis in Southeastern Brazil. J Med Entomol 46: 42-50.

CEPAGRI - Centro de Pesquisas Meteorológicas e Climáticas Aplicadas à Agricultura 2009. [homepage on the internet]. Campinas: clima dos municípios paulistas: a classificação climática de Köeppen para o estado de São Paulo. [updated 2003 Apr; cited 2009 Oct 19]. Avaible from: http://www.cpa.unicamp.br/outrasinformacoes/clima-dos-municipios-paulistas.html.

CIIAGRO - Centro Integrado de Informações Agrometeorológicas 2009. [homepage on the internet]. CIIAGRO on line. Files updated weekly. Updated Oct, 2009. Avaiable from: http://www. ciiagro.sp.gov.br/ciiagroonline/MenuMonClim.htm.

Costa AIP, Casanova C, Rodas LAC, Galati EAB 1997. Atualização da distribuição geográfica e primeiro encontro de Lutzomyia longipalpis em área urbana no estado de São Paulo, Brasil. Rev Saude Publica 31: 632-633.

Dajoz R 1973. Ecologia geral, 2nd ed., Editora Vozes Ltda., Petrópolis, $472 \mathrm{pp}$.
Ferro C, Pardo R, Torres M, Morrison AC 1997. Larval microhabitats of Lutzomyia longipalpis (Diptera: Psychodidae) in an endemic focus of visceral leishmaniasis in Colombia. $J$ Med Entomol 34: 719-728.

Forattini OP 1973. Entomologia médica. Psychodidae, Phlebotominae, Leishmaniose, Bartonelose, Vol. IV, Edgard Blucher, São Paulo, 658 pp.

Galati EAB 2003. Morfologia e taxonomia: morfologia, terminologia de adultos e identificação dos táxons da América. In EF Rangel, R Lainson, Flebotomíneos do Brasil, Editora Fiocruz, Rio de Janeiro, p. 53-176.

Galati EAB, Nunes VLB, Boggiani PC, Dorval MEC, Cristaldo G, Rocha HC, Oshiro ET, Damasceno-Junior GA 2006. Phlebotomines (Diptera: Psychodidae) in forested areas of the Serra da Bodoquena, state of Mato Grosso do Sul, Brazil. Mem Inst Oswaldo Cruz 101: 175-193.

Galati EAB, Nunes VLB, Dorval MEC, Oshiro ET, Cristaldo G, Espíndola MA, Rocha HC, Garcia WB 1996. Estudo dos flebotomíneos (Diptera: Psychodidae) em área de leishmaniose tegumentar no estado de Mato Grosso do Sul, Brasil. Rev Saude Publica 30: 115-128.

Gomes AC 1994. Sand fly vectorial ecology in the state of São Paulo. Mem Inst Oswaldo Cruz 89: 457-460.

Gomes AC, Barata JMS, Rocha e Silva E, Galati EAB 1989. Aspectos ecológicos da leishmaniose tegumentar americana. Rev Inst Med Trop São Paulo 31: 32-39.

Gomes AC, Galati EAB 1987. Aspectos ecológicos da leishmaniose tegumentar americana. 5. Estratificação da atividade espacial e estacional de Phlebotominae (Diptera: Psychodidade) em áreas de cultura agrícola da região do Vale do Ribeira, estado de São Paulo, Brasil. Mem Inst Oswaldo Cruz 82: 467-473.

Katz G 1997. Epidemiologia da leishmaniose tegumentar americana no estado de São Paulo, MSc Dissertation, Faculdade de Medicina, Universidade de São Paulo, São Paulo, 134 pp.

Lainson R 1989. Demographic changes and their influence on the epidemiology of the American leishmaniases. In MW Service, Demography and vector-borne diseases, CRC Press, Boca Raton, p. 85-106.

Magurran AE 1988. Ecological diversity and its measurement, Princeton University, Princeton, 177 pp.

Mayo RC, Casanova C, Mascarini LM, Pignatti MG, Rangel O, Galati EAB, Wanderley DMV, Corrêa FMA 1998. Flebotomíneos (Díptera: Psychodidae) de área de transmissão de leishmaniose tegumentar americana, no município de Itupeva, região sudeste do estado de São Paulo, Brasil. Rev Soc Bras Med Trop 31: 339-345.

Mayrink W, Williams P, Coelho MV, Dias M, Martins AV 1979. Epidemiology of dermal leishmaniasis in the Rio Doce Valley, state of Minas Gerais, Brazil. Ann Trop Med Parasitol 73: 123-137.

Morrison AC, Ferro C, Pardo R, Torres M, Devlin B, Wilson ML, Tesh RB 1995. Seasonal abundance of Lutzomyia longipalpis (Diptera: Psychodidae) at an endemic focus of visceral leishmaniasis in Colombia. J Med Entomol 32: 538-548.

Oliveira AG, Andrade Filho JD, Falcão AL, Brazil RP 2003. Estudo de flebotomíneos (Diptera: Psychodidae: Phlebotominae) na zona urbana da cidade de Campo Grande, Mato Grosso do Sul, Brasil, 1999-2000. Cad Saude Publica 19: 933-944.

Rangel EF, Lainson R 2003. Flebotomíneos do Brasil, Editora Fiocruz, Rio de Janeiro, $360 \mathrm{pp}$.

Rangel O, Vido A 1997. Fauna flebotomínea de leishmaniose tegumentar americana na região de São João da Boa Vista-SP. Rev Patol Trop 26: 17-24. 
Resende MC, Camargo MCV, Vieira JRM, Nobi RCA, Porto Oliveira CL, Pessanha JE, Cunha MCM, Brandão ST 2006. Seasonal variation of Lutzomyia longipalpis em Belo Horizonte, estado de Minas Gerais. Rev Soc Bras Med Trop 39: 51-55.

Roberts DR, Hsi BP 1979. An index of species abundance for use with mosquito survillance data. Environ Entomol 8: 1007-1013.

Rutledge LC, Ellenwood DA 1975. Production of phlebotomine sandflies on the open forest floor in Panama: hydrologic and physiographic relations. Environ Entomol 4: 78-82.

Service MW 1993. Mosquito ecology: field sampling methods, Chapman Hall, London, 988 pp.

SES/SUCEN/CCD - Secretaria de Estado da Saúde/Superintendência de Controle de Endemias/Coordenadoria de Controle de Doenças 2008. Atualização da classificação epidemiológica dos municípios para a leishmaniose visceral americana. Bol Epidemiol Paulista 5: 18-25.

Shaw JJ, Lainson R 1987. Ecology and epidemiology: New World. In W Peters, R Killick-Kendrick (eds), The leishmaniases in biology and medicine, Vol. 1, Academic Press, London, p. 291-363.
Shimabukuro PHF 2007. Chave de identificação ilustrada dos Phlebotominae (Diptera: Psychodidae) do estado de São Paulo, $\mathrm{PhD}$ Thesis, Secretaria de Estado da Saúde, Coordenadoria de Controle de Doenças, São Paulo, 121 pp.

Silva AM, Camargo NJ, Santos DR, Massafera R, Ferreira AC, Postai C, Cristóvão EC, Konolsaisen JF, Bisetto Jr A, Perinazo R, Teodoro U, Galati EAB 2008. Diversidade, distribuição e abundância de flebotomíneos (Diptera: Psychodidae) no Paraná. Neotrop Entomol 37: 209-225.

Souza GD, Santos E, Andrade Filho JD 2009. The first report of the main vector of visceral leishmaniasis in America, Lutzomyia longipalpis (Lutz \& Neiva) (Diptera: Psychodidae: Phlebotominae), in the state of Rio Grande do Sul, Brazil. Mem Inst Oswaldo Cruz 104: 1181-1182.

Thornthwaite CW, Mather JR 1955. The water balance. Publications in climatology, Drexel Institute of Technology Laboratory of Climatology, Centerton, 104 pp.

Tolezano JE 1994. Ecoepidemiological aspects of American cutaneous leishmaniasis in the state of São Paulo, Brazil. Mem Inst Oswaldo Cruz 89: 427-434. 